\title{
Total Gleason Score for Prostate Cancer
}

National Cancer Institute

\section{Source}

National Cancer Institute. Total Gleason Score for Prostate Cancer. NCI Thesaurus.

Code C48602.

The value of the sum of the primary and secondary Gleason scores (range 2-10). If three patterns are identified, it is the sum of the primary pattern score and the score of the least well-differentiated pattern. 